ARTIGO

\title{
Democracia e luta antimanicomial: imagens de uma disputa incessante
}

\author{
Democracy and the anti-asylum struggle: images of an unceasing dispute \\ Lais Medeiros AMADO* \\ https://orcid.org/oooo-00o2-7599-1414
}

\section{Danichi Hausen MIZOGUCHI**}

https://orcid.org/o0oo-0002-7147-3521

\begin{abstract}
Resumo: Na política contemporânea brasileira, um panorama de suspensão de direitos ameaça as conquistas do movimento antimanicomial. Atentos ao contexto que se impõe e ao consequente enfraquecimento de práticas coletivas e militantes, o presente artigo busca refletir sobre as disputas que envolvem Estado, democracia e luta antimanicomial e explorar formas de enfrentamento ao cenário atual. Para tanto, partimos metodologicamente da experiência de uma estudante de psicologia, suas primeiras inserções de estágio, seu posterior trabalho na rede de saúde mental, e ainda, sua vivência no movimento antimanicomial. Aliados ao pensamento de autores como Gilles Deleuze, Judith Butler e Suely Rolnik, concluímos que os caminhos ligados à ocupação da cidade são modos imprescindíveis de embate frente à desvalorização da vida e ao estigma da loucura.
\end{abstract}

Palavras-chave: Democracia. Luta Antimanicomial. Cidade.

Abstract: In contemporary Brazilian politics the suspension of rights threatens the achievements of the anti-asylum movement. Paying attention to the prevailing context and the consequent weakening of collective and militant practices, this article reflects on disputes involving the State, democracy and the anti-asylum struggle and explores ways of confronting the current situation. To do so, we start from the experiences of a psychology student, her first internship, her later work in the mental health network, and her experiences of the anti-asylum movement. Combining the thoughts of authors such as Gilles Deleuze, Judith Butler and Suely Rolnik, we conclude that the pathways linked to the occupation of the city are essential ways of confronting the devaluation of life and the stigma of mental illness.

Keywords: Democracy. Anti-asylum Struggle. City.

Submetido em: 15/5/2020. Revisado em: 20/9/2020. Aceito em: 7/11/2020.

\footnotetext{
* Psicóloga. Mestre em Psicologia pela Universidade Federal Fluminense. Psicóloga em Fundação de Apoio à Fiocruz (Fiotec, Rio de Janeiro, Brasil). Av. Brasil, 4036, Manguinhos, Rio de Janeiro (RJ), CEP 21040-361. E-mail: laism.amado@gmail.com.

** Psicólogo. Doutor em Psicologia pela Universidade Federal Fluminense. Professor Adjunto do Departamento e do Programa de Pós-graduação em Psicologia da Universidade Federal Fluminense. Rua Alexandre Moura, 8, São Domingos, Niterói (RJ), CEP. 24210-200. Email: danichihm@hotmail.com.
} copiar e redistribuir o material em qualquer suporte ou formato, bem como adaptar, transformar e criar a partir deste material para qualquer fim, mesmo que comercial. O licenciante não pode revogar estes direitos desde que você respeite os termos da licença. 


\section{Guardando sonhos}

$\mathrm{N}$ iterói, 2010. Defronte ao prédio do curso de Psicologia da Universidade Federal Fluminense vê-se um extenso e bem aparado gramado, no qual boa parte das alunas e dos alunos se reúne para matar aula, jogar bola e conversar. Amarrados aos galhos de um flamboyant, tecidos coloridos sustentam acrobacias realizadas alguns metros acima do chão. Entre flertes, beijos e baseados, alguém toca um violão. Nas mesinhas dos pilotis, joga-se xadrez, leem-se e discutem-se os textos que embasam as matérias. Edifícios em construção, novos concursos para docentes, mais vagas para estudantes e cursos inéditos são índices importantes do processo de expansão do ensino público gratuito e de qualidade que se prometia naquele momento.

Para muitos dos jovens estudantes, o Diretório Acadêmico da Psicologia é o lugar mais revolucionário do mundo. Localiza-se em uma sala apertada, nos fundos do andar térreo, em cujo interior encontram-se tão somente um sofá puído, duas ou três cadeiras e um armário acumulando papel e pó. É ali que se organizam festas, rodas de conversa e semanas acadêmicas que ajudarão a construir um outro mundo possível. Nas paredes, pichações anunciam juras de amor, prazer e militância. Impregnada pelo cheiro de cigarro e de pipoca de micro-ondas, a sala, que sequer tem janelas, guarda os sonhos daqueles que varam a noite ali - e que, dentre outras batalhas descobertas e anunciadas durante os cinco anos de graduação, se apaixonam pela alegria que transparece na luta antimanicomial.

Os sonhos alegres de uma sociedade sem manicômios se atualizam já nas primeiras experiências com a loucura, como no dia em que a estagiária novata no Centro de Atenção Psicossocial vê um rapaz muito jovem chegar acompanhado de sua mãe. A senhora diz não poder mais cuidar do filho: "SPT", afirma, "ele é SPT. Sem possibilidades terapêuticas". O usuário de drogas infectado pelo vírus HIV já acumula tantos diagnósticos e tratamentos frustrados que, para aquela mãe, só parece restar a descrença e a desesperança.

No interior da sala de atendimento, a expressão indócil do rapaz fita a equipe com desprezo. A estagiária recém-chegada senta-se em frente ao rapaz e assume uma posição discreta. Carrega uma caneta e uma ficha nas mãos, com a pretensão de anotar tudo quanto puder, e olha sem cessar para as profissionais que a acompanham, esperando que digam exatamente o que fazer. $\mathrm{O}$ rapaz carrega nos gestos o estereótipo do carioca marrento, mas as responsáveis por conduzir o atendimento o traduzem como o Menino do Rio cantado por Caetano Veloso. A estagiária, com a prancheta nas mãos e o olhar discreto, supõe que esteja ali para preencher a anamnese, mas se espanta quando as duas profissionais levantam e começam a cantar. Fazem piadas e dançam em torno do rapaz, performatizando com gestos e com palavras o dragão tatuado no braço, o calção corpo aberto no espaço e o coração de eterno flerte. Em música, dança e riso, elas pedem para Deus proteger-lhe. As trabalhadoras fogem a toda e qualquer prescrição ou protocolo, fazendo aquela ficha nas mãos da jovem estagiária perder completamente o sentido. Anos depois, não há mais lembrança de 
como o atendimento termina, mas as gargalhadas do Menino do Rio permaneciam vivas em algumas memórias - e parece que ninguém ainda o tinha visto sorrir.

\section{Sem saber por onde seguir}

Rio de Janeiro, 2018. A jovem estagiária agora é psicóloga e atua em um Centro de Atenção Psicossocial (CAPS) responsável pelo cuidado em saúde mental da população do Jacarezinho. ${ }^{1}$ Precisa fazer o atendimento domiciliar de uma jovem recém-chegada ao serviço. Faz parte do protocolo de trabalho averiguar como está o território - verde, amarelo ou vermelho ${ }^{2}$-, e, como de costume, ela liga para a Clínica da Família da região antes de sair para realizar a consulta.

Recebe a informação de que o sinal está verde e, sem receios, vai de ônibus. O CAPS possui motorista, mas o carro está sem gasolina e o profissional sem salário. Cinco, dez, quinze, vinte minutos esperando o transporte - que, quando chega, vem lotado. São cerca de trinta ou quarenta minutos sacolejando em pé até puxar a cordinha, pedir licença e agradecer ao motorista. Salta em frente ao metrô para encarar mais vinte minutos de deslocamento - agora ao menos com ar condicionado e a possibilidade de sentar, mesmo que no chão. A estação de destino fica a dez minutos a pé da Clínica. A caminhada é curta e a paisagem intrigante: no pequeno trecho contrastam o batuque da escola de samba, o entra e sai de homens armados da Cidade da Polícia e o odor vindo da SUIPA - a Sociedade União Internacional Protetora dos Animais, que fica embaixo do viaduto que corta a Zona Norte do Rio de Janeiro e cujas paredes com marcas de tiro estão coladas à estrutura do container onde funciona a Clínica da Família.

A psicóloga chega um tanto suada e já cansada. Entra pelo corredor lateral e vai até o refeitório onde duas enfermeiras e uma médica conversam enquanto passam um café. Os cheiros se misturam às histórias trocadas ali. Uma profissional, aflita, abre a porta. É a Agente Comunitária de Saúde que estava à sua espera. Com as mãos trêmulas, a colega a abraça e pede um copo d'água. Tinha acabado de receber a notícia do falecimento de uma usuária que estava grávida. Mesmo tendo a gravidez dita de risco acompanhada de perto pela Clínica, ela deu azar - é o que a funcionária afirma -, pois "a bolsa rompeu em uma péssima hora, durante as quase sete horas ininterruptas de tiroteio na região. A moça morreu antes de poder ser levada ao hospital. Por sorte salvaram o bebê". A Agente Comunitária de Saúde bebe toda a água e enche o copo de café. O suor pinga em sua face. Depois de alguns minutos, ela e a psicóloga seguem juntas por entre as vielas do Jacarezinho. O sinal está verde, mas nenhuma das duas parece saber por onde seguir.

\footnotetext{
${ }^{1}$ Jacarezinho é uma das maiores favelas do Rio de Janeiro, situada na Zona Norte da cidade.

2 Refere-se a um protocolo adaptado de países em guerra, criado pela Cruz Vermelha, que treinou profissionais da Secretaria Municipal de Saúde. Se o alerta for vermelho, significa que as unidades de saúde precisam ser fechadas devido aos conflitos no território e ao risco que correm profissionais e usuários. O alerta amarelo indica a suspensão de atividades externas, como visitas domiciliares e atividades de promoção de saúde. Por fim, o sinal verde significa o funcionamento normal do serviço.
} 


\section{Democracia e luta antimanicomial}

Logo após a morte de Michel Foucault, Gilles Deleuze inaugura a reaproximação póstuma que teria ao menos dois momentos marcantes: a ministração do curso dos anos de 1985 e 1986 no Centre Universitaire de Vincennes e a publicação do livro que dele se originou, intitulado tão somente Foucault. É neste curso, na aula do dia 6 de maio de 1986, que Deleuze, na tentativa de mapear o surgimento de um "[...] novo espaço cósmico e social” (DELEUZE, 2017, p. 195), anuncia uma certa relação fundamental entre a democracia e a filosofia. Nesta aula, Deleuze nos diz que o pensamento pré-filosófico é um pensamento mágico-religioso. Para este pensamento, no começo de tudo está o caos - a partir do qual, em uma história mítica de guerra entre os deuses, deu-se a vitória do mais forte deles, Zeus, com cuja supremacia fez-se a ordem.

O pensamento mágico-religioso, portanto, é aquele que se preocupa em traçar a história de todas as disputas entre as gerações de deuses - tudo aquilo que se passou entre o caos inicial e a ordem imposta pela vitória de Zeus: a história da luta entre os titãs até que o maior de todos eles se impusesse - impondo, simultaneamente, ordem ao caos. O pensamento pré-filosófico, portanto, apresentava a hierarquia de potências divinas em luta umas contra as outras: tratava-se de uma ontologia da guerra e da hierarquia. Não parece estranho que o jogo político que vicejava nesse momento fosse imperial, tornando claro o encaixe pleno e perfeito entre o modo social e o modo de pensamento vigentes.

De acordo com Deleuze, o jogo filosófico é aquele que tem outro princípio; o jogo filosófico é aquele que diz, de saída, que o universo tem uma lei de organização imanente. Esta mudança de concepção cósmica - da ordem como imposição mediada pela guerra à ordem imanente - se dava em paralelo a uma mutação importantíssima do espaço social grego. Tratava-se de um terreno supostamente definido pela isonomia, espécie de condição de igualdade que passa a reger a vida dos homens livres. Sob o princípio da isonomia - um novo princípio do direito a partir do qual todos os cidadãos são iguais perante a lei - forjava-se um espaço social homogêneo cujas partes estavam todas à mesma distância em relação ao centro.

Isso certamente era efeito, em primeiro lugar, da grande constituição posta em voga por Clístenes, em 508 a. C., que realizou uma reforma política que proporcionou a todos os cidadãos, independentemente de qualquer critério de renda, o direito de votar e de ocupar cargos públicos. Com esta constituição, todos os cidadãos podiam participar da assembleia popular - assembleia que certamente tinha as limitações típicas gregas, pois era restrita ao que então se chamava de cidadãos: homens atenienses maiores de 18 anos, filhos de pai e mãe atenienses, excluindo-se taxativamente da categoria as mulheres, os estrangeiros e os escravos.

A constituição promulgada por Clístenes realizou uma repartição do espaço social, fazendo com que doravante todo e qualquer cidadão esteja à mesma distância do centro: sob Clístenes, a ágora substituiu a pirâmide. Deleuze destaca que o espaço social da democracia se organiza de tal modo que com ele são ofertadas condições de 
possibilidade à invenção de um modo discursivo ao qual se chamará filosófico. A condição de possibilidade da filosofia é, portanto, uma alteração geopolítica do espaço público: da geopolítica da pirâmide à geopolítica do círculo, da verticalidade estrutural do espaço da pólis à equidistância do centro na ágora grega. Isto porque, sob a mesma distância do centro, o que aparece é a abertura de um campo enunciativo em que os cidadãos já não mais guerreiam entre si, mas argumentam - ou seja, com esta alteração político-espacial, a palavra, o discurso e a verdade ganham um novo estatuto na cidade.

Nesse grande jogo político, o que aparece é um novo tipo de forças. A filosofia, sob a democracia, é uma nova aventura das forças e das relações de forças, forjando o que pode ser chamado de uma relação agonística entre agentes livres. E o que aparece na cidade grega, a partir da ágora, é uma relação de rivalidade - política, judicial, amorosa - entre cidadãos livres. Isto porque em um espaço de isonomia, em que os cidadãos ocupam a mesma distância em relação ao centro, para qualquer questão que seja colocada, os gregos já não esperam que o soberano decida a rusga, tampouco guerreiam com armas de ferro para decidir quem é o vencedor. Sob o jogo democrático da ágora, os gregos doravante argumentam - e argumentam estando à mesma distância de um centro, de um centro vazio que pode ser ocupado por qualquer um. A relação agonística entre agentes livres forja, portanto, a enunciação filosófica entendida como multiplicação da disputa de sentidos acerca das escolhas e dos destinos da cidade, impondo uma relação irmanada entre a filosofia e a democracia.

Em tempos muito próximos à invenção quase simultânea de filosofia e de democracia, Platão questionava as possibilidades reais de efetivação de um modelo pautado pela isonomia em uma cidade como Atenas. E embora Deleuze pareça ir um tanto rápido demais na argumentação conduzida na aula aqui citada, fica claro que a objeção platônica não significava em absoluto o desejo de retorno ao modelo pré-filosófico mágico-religioso, mas o reconhecimento da impossibilidade de efetivação da igualdade democrática por completo. É que ele já indicava aquilo que mais recentemente Judith Butler (2018) tem indicado: que as noções de igualdade democrática são abaladas sempre que se decide "[...] quais saúdes e vidas devem ser protegidas e quais não devem [...]" (BUTLER, 2018, p. 17) - e que é isso que recorrentemente ocorre, mesmo que formalmente o regime estatal seja democrático.

Pois não seria com o advento de um novo modo de organização espacial e discursiva dito democrático-filosófico - que desapareciam as marcas de um embate violento que preponderava anteriormente. E se talvez não se trate de um retorno ao modo político imperial, a questão política por excelência - e que hoje, no Brasil, ganha caráter de urgência - interroga necessariamente as possibilidades de ampliação do campo discursivo e político democrático. Assim, passamos a compreender a democracia desde sua origem grega até os dias de hoje - não como algo estático ou garantido, mas, ao contrário, como aquilo que performatiza um movimento incessante de disputa e expansão, no qual a luta para que mais pessoas estejam disputando o espaço e o sentido das coisas é permanente e infindável. 
O perverso caminho da democracia ao fascismo vivido no Brasil - que António Negri chamou de "[...] linear, organizado não por movimentos extremos, mas pelas mesmas instituições do poder constitucional [...]” (NEGRI, 2019, p. 10) - desvela um projeto coerente que atravessa as instituições, incidindo nas figuras formais da constituição e “[...] dissipando qualquer caráter ético do princípio democrático [...]” (NEGRI, 2019, p. 10) - o que necessariamente toca a luta por uma sociedade sem manicômios, desde que entendamos que ela é, também, uma luta por democracia.

Hoje, a lembrança daquela pequena sala que guardava sonhos destoa do ambiente nebuloso de um país em que uma série de retrocessos políticos nos mais diversos níveis da gestão é anunciada quase diariamente: a Proposta de Emenda Constitucional que congela gastos públicos por vinte anos, a Reforma Trabalhista que muda significativamente a Consolidação das Leis do Trabalho e a Reforma da Previdência que torna as regras de concessão das aposentadorias ainda mais difíceis ${ }^{3}$ são apenas alguns dos índices mais gritantes e grandiloquentes de um certo aspecto de terra arrasada que se alastra no cotidiano nacional.

Não provoca espanto, portanto, que os partidários da indústria da loucura defendam hoje uma espécie estranha de reformulação nas políticas de acolhimento à saúde mental - chamada também de Segunda Reforma Psiquiátrica - sustentada na posição contraditória da nota técnica segundo a qual “[...] não cabe mais a ideia de que hospitais psiquiátricos devam abrigar moradores. Porém, também não cabe mais a ideia de que tais Serviços devam ser fechados” (BRASIL, 2019, p. 8). Diante do retrocesso brutal, o que aparece é a sensação de que alguns embates ainda são os mesmos de mais de trinta anos atrás, e que certas forças conservadoras parecem nunca ter cessado, "[...] mas apenas feito um recuo estratégico temporário à espreita de condições favoráveis para sua volta triunfal, retomando seu looping que parece nunca ter fim [...]" (ROLNIK, 2018, p. 100) em um país cujo passado dificilmente é ultrapassado e cuja democracia sempre se sustenta em pés de barro.

É verdade que uma boa dose de romantização e um tanto de ingenuidade em relação à conjuntura política permeavam o ambiente estudantil no começo da segunda década dos anos 2000. Afinal, no mesmo momento em que boa parte daqueles sonhos se davam, já se faziam notórias as "[...] alianças espúrias, a supremacia do poder empresarial sobre o poder público e o interesse dos cidadãos [...]” (ROLNIK, 2018, p. 151) - e certamente com isso já fazia fraquejar ou equivocar boa parte das apostas daqueles que acreditavam que um outro mundo é possível. Todavia, talvez ali já se pudesse indicar uma certa entonação necessária à luta democrática à qual gostaríamos de chamar de micropolítica - distinta, porém inseparável da dimensão macropolítica.

Na segunda metade dos anos 1970 e na década de 1980, na conjuntura de embates contra a ditadura militar, emergiram diferentes movimentos sociais advindos de três

\footnotetext{
3 A Proposta de Emenda Constitucional 55/2016, também conhecida como PEC do fim do mundo, congela gastos públicos por vinte anos sob o argumento da crise econômica. Também sob a justificativa da crise, a Reforma Trabalhista é instrumentalizada pela lei $\mathrm{n}^{0} 13.467$ de 2017; e, por fim, a Reforma da Previdência é consolidada pela PEC 06/2019.
} 
grandes frentes de luta: a Teologia de Libertação, a política partidária e o sindicalismo (MONTEIRO; COIMBRA; MENDONÇA FILHO, 2006). Tais movimentos fizeram parte de uma estratégia coletiva de resistência cujas transversais foram a luta por liberdades democráticas materializadas pela conquista de espaços, expressões e valores distintos daqueles impostos pelo capitalismo internacional através da ditadura civil, empresarial e militar que vicejou por vinte e um anos no Brasil. Mesmo que marcados pela lógica partidária representativa, esses movimentos sociais fizeram aparecer um modo de pensar e fazer a política distinto de algumas diretrizes estabilizadas no status quo da esquerda ao enfatizarem a dimensão cotidiana, microfísica e capilar da disputa dimensão esta que era tradicionalmente desconsiderada ou pouco considerada pelos movimentos majoritários de resistência (MONTEIRO; COIMBRA; MENDONÇA FILHO, 2006).

No entanto, mesmo com a força dessas três grandes frentes de luta, no processo da suposta redemocratização brasileira, "[...] é a dimensão macro, com seus lugares de poder estabelecidos pela lógica da representação partidária que vai sendo privilegiada: o da conquista de um lugar de poder que se acreditava estar localizado no Estado" (MONTEIRO; COIMBRA; MENDONÇA FILHO, 2006, p. 10).

Se evidentemente é verdade que novas experiências surgiram na luta pelas liberdades democráticas, com forças coletivas dando passagem a outras formas de expressão da resistência e da esquerda, também é verdade que uma certa lógica de lugares que tradicionalmente nutre o exercício do poder permaneceu intocada. $\mathrm{O}$ contexto autoritário findou por fazer com que se buscasse a conquista de um Estado Democrático de Direito - meta que aparecia como única possibilidade de enfrentamento aos poderes estabelecidos nos vinte e um anos de ditadura. Buscou-se, assim, ocupar estes lugares de poder na suposição de que, ao se exercer o poder de Estado, seria possível usá-lo de outra maneira. O que talvez reste eclipsado nesta grade de compreensão é o fato de que todo lugar de poder instituído, como inequivocamente é o aparelho de Estado, funciona a partir de uma lógica estabelecida, e que ocupa-lo é, "[...] na maior parte das vezes, servi-lo na condição de operador de seus dispositivos" (MONTEIRO; COIMBRA; MENDONÇA FILHO, 2006, p. 11). Deste modo, mesmo com a extrema dificuldade de "[...] transformar o funcionamento das máquinas estatais capitalísticas, mantém-se a crença na possibilidade de reformas através de intervenções nas formulações e implementações de políticas públicas vinculadas ao Estado" (MONTEIRO; COIMBRA; MENDONÇA FILHO, 2006, p. 11).

Assim, talvez seja necessário desviar a relação naturalizada entre o Estado e as políticas públicas, fazendo com que não sejam termos necessariamente coincidentes. Os domínios do Estado e do público não se justapõem, desde que se entenda que o público "[...] diz respeito à experiência concreta dos coletivos de forças sempre em movimento [...]” (MONTEIRO; COIMBRA; MENDONÇA FILHO, 2006, p. 11) ocupando, portanto, um plano diferente do Estado, entendido como "[...] figura paralisada e transcendente da modernidade" (MONTEIRO; COIMBRA; MENDONÇA FILHO, 2006, p. 11). Sob esta grade de compreensão da relação entre a democracia, o Estado e a luta, talvez se deva problematizar cada vez mais os motivos que nos levam a permanecer conectados quase que exclusivamente ao mito da democracia 
representativa - e, a reboque, às forças reativas e ao ressentimento - ao invés de afirmarmos a força inventiva da micropolítica - que eclode o tempo todo na pequenez do cotidiano.

No célebre Manifesto de Bauru (1987), já se indicava que a luta antimanicomial não pode se fazer sem abranger também "[...] a opressão nas fábricas, nas instituições de adolescentes, nos cárceres, a discriminação contra negros, homossexuais, índios, mulheres" (MANIFESTO DE BAURU, 1987, p. 1). Ali, o recém-inaugurado movimento por uma sociedade sem manicômios já afirmava que a luta não se reduz à extinção dos hospitais psiquiátricos - ainda que este seja um princípio e uma meta inegociáveis -, mas que, mais amplamente, se faz em defesa da criação de um outro mundo.

Quando da ascensão do movimento antimanicomial, portanto, entendia-se que lutar por uma sociedade sem manicômios era lutar também pela democratização da sociedade nos mais diversos âmbitos - lutar, portanto, por outros modos de vida. Neste contexto, experiências como a $8^{\mathrm{a}}$ Conferência Nacional de Saúde, realizada em março de 1986, marcaram definitivamente o caráter da Reforma Sanitária ao abrir pela primeira vez essa estirpe de espaço deliberativo à participação da sociedade civil tornando evidente, assim, a necessidade do debate e do dissenso para o avanço das pautas democráticas em um país que àquele momento queria e necessitava se afastar das marcas do estado de exceção vigente por mais de duas décadas.

A movimentação que induz a sociedade civil à participação ativa na construção das políticas públicas exemplifica a disputa pela ampliação democrática tão em voga naquele momento - em um gesto coetâneo ao efetivado no âmbito do legislativo e do executivo com a promulgação e a execução de leis que protegem e ampliam os mais diversos direitos humanos. No âmbito dos movimentos sociais, a transformação do Movimento de Trabalhadores em Saúde Mental em Movimento Nacional da Luta Antimanicomial expressa a passagem do protagonismo dos trabalhadores ao protagonismo dos usuários, trabalhadores, familiares e amigos da luta antimanicomial, equiparando em direitos de voz e voto todos aqueles que almejam uma sociedade sem manicômios. Se falar de democracia é necessariamente falar desse movimento incessante, então sonhar e lutar por uma sociedade sem manicômios parece nada mais do que lutar pela expansão desse mesmo jogo democrático. E o que seria a afirmação democrática e a luta antimanicomial, desde sempre, se não o esforço militante pela ampliação do campo da disputa de sentidos na cidade sempre em vias de se fazer?

\section{Micropolíticas da ocupação}

Rio de Janeiro, 2011. Sob a inspiração de ações globais expressivas como a Primavera Árabe no Egito, a Porta do Sol na Espanha e o Ocuppy nos Estados Unidos, inúmeras barracas ocupam a praça da Cinelândia por meses. O acampamento reúne pessoas que se dizem descontentes com o estado geral de coisas na democracia representativa. Simultaneamente interrogam e diagnosticam: "Que democracia é essa? Pra quem é essa democracia? Porque eu só vejo ditadura pra gente". ${ }^{4}$

4 Fala extraída do vídeo intitulado Ocupa Rio Cinelândia (2011). 
Muitos setores alocados macropoliticamente à esquerda, acostumados a classificar todos os corpos em luta simplesmente como proletários, se viam embaraçados com os novos movimentos de insurreição e alegavam "[...] falta de senso de oportunidade do movimento para avançar uma pauta de reivindicações concretas capaz de mobilizar a sociedade civil" (TEIXEIRA, 2011, não paginado). Dizia-se que aqueles que se levantam não têm "[...] nada para colocar no trono, à parte, talvez, de um ponto de interrogação" (INVISIVEL, 2016, p. 51).

Todavia, a estratégia rara e pouco afeita à tradição de militância política ressoou vigorosamente nos campos da saúde e da educação. As ocupações de escolas, universidades e diferentes sedes do Ministério da Saúde carregavam reivindicações específicas e se davam metodologicamente sob um modo de insurgência que apostava nas assembleias, na partilha do cotidiano e na tomada comunitária de decisões. O que se via então era "[...] uma batalha sobre o significado de democracia, batalha essa que nem sempre assume a forma de uma deliberação [...]" (BUTLER, 2018, p. 8), já que esses movimentos de insurreição contemporâneos "[...] já não partem de ideologias políticas, mas de verdades éticas” (INVISIVEL, 2016, p. 53). O que se vê nos levantes contemporâneos é que não são nem "[...] a arraia-miúda, nem a classe operária, nem a pequena burguesia, nem a multidão que se revolta. Nada que apresente uma homogeneidade suficiente para admitir um representante" (INVISIVEL, 2016, p. 51).

Se há nesses levantes uma batalha pelo significado de democracia, pelo seu modo de exercício, reduzir a expressividade desses movimentos ao grito uníssono por um novo governo pode deixar escapar a dimensão implícita da "[...] reivindicação por poder se unir, se reunir em assembleia, e de fazê-lo livremente, sem medo da violência policial ou da censura política” (BUTLER, 2018, p. 23), já que

[...] o comparecimento, a permanência, a respiração, o movimento, a quietude, o discurso e o silêncio são [...] uma forma imprevista de performatividade política que coloca a vida possível de ser vivida no primeiro plano da política. E isso parece estar acontecendo antes que qualquer grupo exponha suas exigências ou comece a se explicar em termos propriamente políticos (BUTLER, 2018, p. 24).

Tal configuração de embates parece se aproximar daquilo que Suely Rolnik (2018) indica como norte ético para aqueles que acreditam que um outro mundo é possível: "[...] uma distribuição de lugares menos assimétrica - no âmbito social, econômico e político -, bem como um Estado que sustente essa ampliação da igualdade” (ROLNIK, 2018, p. 118). Certamente é preciso lembrar que estamos diante do que a mesma Rolnik (2018) detecta e diagnostica como um cenário estatal macropolítico inédito, fruto da união incomum e temporária entre as forças reativas do conservadorismo e do neoliberalismo que operam a favor de um retrocesso amplo, geral e irrestrito do campo democrático.

Neste cenário, a autora afirma que o problema está em esquecer ou desvalorizar a esfera micropolítica, dado que

[...] se aceder a direitos civis é essencial, no entanto a redução a essa meta e, sobretudo, a partir de uma negação da experiência singular de tais agentes 
sociais e de seu direito de existir - a qual é substituída pelas esquerdas por uma caricatura identitária - tende a levá-los a uma adaptação submissa ao modo hegemônico de subjetivação (ROLNIK, 2018, p. 119).

Isso porque, como há muito já é sabido, para que as quedas dos muros dos hospícios sejam de fato efetivas, transformadoras daquilo que nomeamos como estigma da loucura, a derrocada dos muros de concreto precisa vir acompanhada da quebra de um olhar racionalista por séculos impregnado em nós (PELBART, 1990). Para tanto, é fundamental que não nos esqueçamos de algumas interrogações, como, por exemplo: que estratégias temos cunhado em nome do direito à desrazão, e sob que outros modos de luta estamos interessados em fazer operar o jogo democrático do qual esse direito faz parte? Afinal, de que modo temos enfrentado os perigos que nos cercam, nos entristecem e tentam nos fazer desistir?

\section{Festa e insistência}

Rio de Janeiro, 2018. Diferente da última festa, desta vez não chove. O largo que ostenta a estátua de Mercedes Baptista - a primeira bailarina negra a compor o corpo de baile do Teatro Municipal - está lotado. O museu que funciona nas proximidades inaugura a exposição O Rio dos Navegantes com um show de Teresa Cristina. Sobrados antigos que hoje funcionam como bares, casas de festa e restaurantes estão à espera de clientes. São espaços charmosos e um tanto apertados, e um deles é o escolhido para a festa anual da luta antimanicomial.

Subindo-se dois lances da escada estreita e de paredes escuras encontra-se um bar, algumas mesas e uma pista de dança modesta. Com os organizadores atrasados e a decoração por fazer, cada um que chega recebe uma função: falar com o gerente, receber os DJs, tentar quebrar o tom neutro do local com fitas e faixas coloridas. No chão da pista de dança espalham-se as tintas e os pinceis que são o convite para que todos criem seus cartazes. Frases escritas nas cartolinas afirmam que prisões nem as de amor e que loucos são os que se apaixonam. A festa vai começar.

O funk já incendeia a pista de dança quando a música é interrompida. São quatro horas da manhã no momento em que o som pifa. Ouvem-se murmurinhos descontentes. Uma dose de desespero, outra de decepção. Cinco minutos de expectativa e a esperança não satisfeita de que tudo volte ao normal. Aos corpos embriagados na pista de dança resta conferir as tomadas, conectar os fios e girar sem cessar os botões - gestos de quem quer insistir, apesar de tudo. "A cerveja está para acabar”, anuncia o garçom. Alguns descem as escadas desapontados e se despendem dos amigos. Outros pedem a última long neck e acendem mais um cigarro. A cada cerveja o relógio avança, mas ninguém quer ir embora. Do lado de fora, o céu escuro da madrugada. Do lado de dentro, o clarão das luzes já acesas.

Entre inúmeras tentativas frustradas de reestabelecer a música, alguém pede a atenção, e diz com entusiasmo que o bar da frente está aberto, pode conectar a mesa de som e receber os que ainda dançam. Velhos militantes, jovens curiosos, trabalhadores, usuários, conhecidos e desconhecidos descem as escadas animados, carregando nas mãos os cartazes antimanicomiais. Apegados aos dizeres libertários, exibem as 
cartolinas coloridas para todos que, àquela altura, ocupam a praça. Juntos e pelas ruas, gritam: Nenhum passo atrás, manicômio nunca mais!.

O bar que acolheu a festa avisa que, por seu espaço ser pequeno e sua estrutura ser um tanto mambembe, a pista de dança teria que ser na rua - na praça, no largo, ao redor de Mercedes, a bailarina que rodopia até o amanhecer. Ao som do funk que volta a incendiar os corpos, coreografias desritmadas recomeçam. São apenas gestos, gestos de insurreição - uma insurreição que "[...] impõe, como qualquer manifestação de envergadura, a sua própria forma de utilização do espaço público" (COMITÊ INVISIVEL, 2016, p. 64). Pelos Becos e Bares, ${ }^{5}$ nenhum movimento isolado garante a retomada de direitos e políticas antimanicomiais, mas juntos compõem um regime "[...] de abertura, de sensibilidade ao que aqui está" (COMITÊ INVISIVEL, 2016, p. 74). Na rua, os corpos em festa indicam que ainda há luta.

Ao amanhecer, amigos sentam na calçada e brindam, distribuem beijos sem parar, saem cambaleantes em busca do pastel da feira - e há os que ainda dançam. São sete horas e os corpos insistem em sonhar e lutar por uma sociedade sem manicômios, a despeito de todos os retrocessos que querem fazer os sonhos guardados em salas e gramados do país inteiro se dissiparem. Às sete horas da manhã, os corpos cansados e alegres carregam, nos mais diminutos gestos, a certeza de que a luta democrática e antimanicomial que se faz pelos becos e pelos bares da cidade jamais terá fim.

\section{Referências}

BRASIL. Ministério da Saúde. Secretaria de Atenção à Saúde. Nota Técnica no 11/2019. Esclarecimentos sobre as mudanças na Política Nacional de Saúde Mental e nas Diretrizes da Política Nacional sobre Drogas. Brasília (DF), 2019. Disponível em: http://pbpd.org.br/wp-content/uploads/2019/o2/o656ad6e.pdf. Acesso em: 2 mar. 2019 .

BUTLER, J. Corpos em aliança e a política das ruas: notas para uma teoria performativa de Assembleia. Rio de Janeiro: Civilização Brasileira, 2018.

COMITÊ INVISIVEL, C. Aos nossos amigos: crise e insurreição. São Paulo: N-1 edições, 2016.

DELEUZE, G. A questão da filosofia na Grécia. Governo de si e subjetivação. Trad. Danichi Hausen Mizoguchi. Revista Mnemosine, Rio de Janeiro, v. 13, n. 1, p. 193-227, 2017. Disponível em: https://www.epublicacoes.uerj.br/index.php/mnemosine/article/view/41718. Acesso em: 12 out. 2019.

MANIFESTO DE BAURU. In: Congresso Nacional de Trabalhadores em Saúde Mental, 2., 1987, Bauru. Brasília (DF), Conselho Federal de Psicologia, 1987. Disponível em:

5 Pelos becos e bares da cidade: liberdade é a frase que dá nome à festa organizada desde 2013 pelo Núcleo Estadual do Movimento da Luta Antimanicomial da cidade do Rio de Janeiro (NEMLA/RJ). A festa é uma estratégia de luta implicada em afirmar que lugar de loucura é na cidade. 
https://site.cfp.org.br/wp-content/uploads/2017/o5/manifesto-de-bauru.pdf. Acesso em: 12 jul. 2019.

MONTEIRO, A.; COIMBRA, C.; MENDONÇA FILHO, M. Estado democrático de direito e políticas públicas: estatal é necessariamente público? Psicologia \&

Sociedade, Recife, v. 18, n. 2, p. 7-12, 2006. Disponível em:

https://www.scielo.br/pdf/psoc/v18n2/o1.pdf. Acesso em: 20 dez. 2018.

NEGRI, A. Primeiras observações sobre o fascismo. São Paulo: N-1 edições, 2019.

OCUPA RIO CINELÂNDIA. [S. l.: s. n.], 2011. 1 vídeo (4 min., 11seg.). Publicado pelo canal linhalimite. Disponível em: http://

https://www.youtube.com/watch?v=VJem_bgogSo. Acesso em: 25 julo. 2019.

PELBART, P. P. Manicômio mental: a outra face da clausura. In: LANCETTI, A. (Org.).

Saúde Loucura 2. São Paulo: Hucitec, 1990. p. 130-138.

ROLNIK, S. Esferas da Insurreição: notas para uma vida não cafetinada. São Paulo:

$\mathrm{N}-1$ edições, 2018.

TEIXEIRA, E. T. A Ocupa Rio e sua inserção no movimento mundial. Passa Palavra, 2011. Disponível em: http://passapalavra.info/2011/11/48081/. Acesso em: 27 jul. 2019.

Lais Medeiros AMADO Trabalhou na concepção, no delineamento, na redação do artigo e aprovação da versão a ser publicada.

Graduada em Psicologia pela Universidade Federal Fluminense. Pós Graduada na modalidade Residência Multiprofissional em Saúde Mental pela Escola de Saúde Mental do Rio de Janeiro (ESAM). Mestre em Psicologia pela Universidade Federal Fluminense. Bolsista de mestrado pela Coordenação de Aperfeiçoamento de Pessoal de Nível Superior (CAPES) entre o mês de setembro de 2018 e agosto de 2019.

Danichi Hausen MIZOGUCHI Trabalhou na redação do artigo e aprovação da versão a ser publicada. Graduado em Psicologia pela UFRGS. Mestrado e Doutorado pela Universidade Federal Fluminense. Pós-doutorado pela Universidade do Estado do Rio de Janeiro. 